\title{
Parametric Study of Ice Thermal Storage System with Thin Layer Ring by Taguchi Method
}

\author{
Junling Xie, Chris Yuan a , \\ ${ }^{a}$ Department of Mechanical Engineering University of Wisconsin, Milwaukee,53211, US
}

\begin{abstract}
A numerical study of material, thickness and arrangement of thin layer ring has been comparatively conducted to achieve heat transfer enhancement in the building thermal storage system. The parameters of thin layer ring from three perspectives have been numerically investigated and optimized by the Taguchi method to find the optimal combination. Nine combinations of model are carried out by combining different levels of each factor, and ice generated area of each combination has been statistically analysed. The results show that material and arrangement of thin layer ring have the most significant impact on the ice formation, but the thickness of thin layer ring has trifling effects on the ice formation. From this study, the optimal combination (A3B2C1) are acquired, and the reproducibility of the results is verified by two analytical results.
\end{abstract}

Keywords: Numerical, Ice formation, Ice thermal storage, thin layer ring, heat transfer enhancement, Taguchi method

* Corresponding author. Tel: +1-414-229-5639

E-mail: cyuan@uwm.edu 


\section{Introduction}

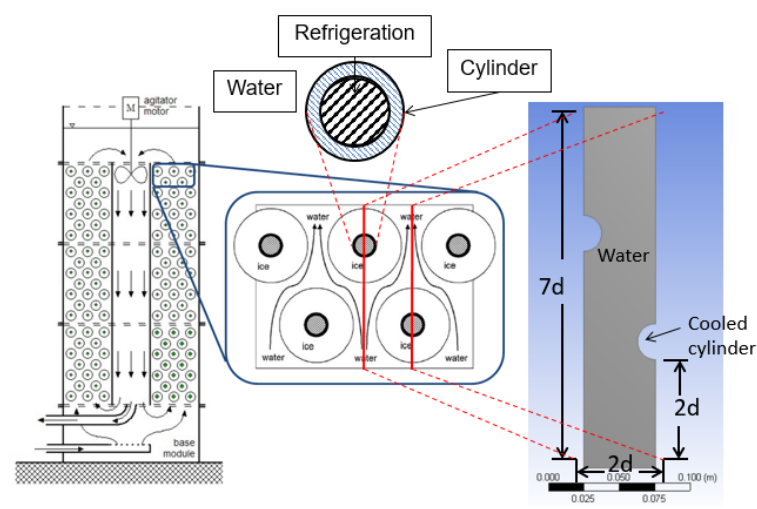

Fig. 1. Geometry of the ITS tank (Left) [28] and the position of analysed rectangular space in the tank (Right) [29]

Nowadays, ice thermal storage (ITS) system with a standard chiller has been widely used to store energy during off-peak hours and release energy during on-peak hours in order to not only reduce energy consumption but also the demand charges during peak hours [1], since thermal conditioning systems such as AC and other refrigeration systems take a share of $16 \sim 50 \%$ of the energy consumption among all the energy used in the building sector [2], while people spend around $90 \%$ of their time in buildings [3]. Using thermal storage system is a cycling process for energy transfer and conservation and provides a comfortable environment for people. Even through energy conservation is widely studied, peak demand conservation was not properly addressed until recently [4-6]. On the electricity bill, peak demand is accounted for $30 \%$ of total charges, so it is the most important because utility companies always require supplying sufficient energy to accommodate the expected increase in peak demand. Due to varying structures of electricity rates and the offered incentives, ITS system has been regarded as the most advanced and cost effective peak demand management method for space cooling [7-10] in different building applications that are mainly occupied during the operating hours, such as office buildings [11], hospitals [12], schools [13][14], and churches and mosques [15]. The offset in electricity demand after using ITS system is accompanied by an improved system performance [16] and reduced total cost [17]. Therefore, technical performance of ITS system has a large impact on continuously improving the energy efficiency and reducing the environmental impact of industrial facilities. Nowadays, water or ice are the most attractive storage materials for HVAC field and have been widely used as phase change material (PCM) [18], since these materials are inexpensive, abundant and safe [19]. However, in the current ITS systems, the solidification of ice is not well developed which not only affects the cooling performance of the system but also wastes energy. In particular, there are some blind areas between the refrigerant cylinders with incomplete ice formation due to inefficient heat transfer which lowers the thermal storage capacity of the system. The duration of ice formation depends on three major heat transfer processes as shown on the top of Fig.1: convection from the heat transfer fluid (refrigerant) to the refrigerant cylinder; conduction within the cylinder; and heat transfer from cylinder to the phase change material (PCM) such as water through conduction and/or convection. In the solidification process, the solid layer generated by PCM on the cylinder surface shortens the heat transfer duration [20].

There are many applications to improve heat transfer in the thermal storage system, but less in the ITS system $[21,22,23,24,25,26]$. Among them, the new application of thin layer ring structure has been demonstrated as an effective way [27]. The results shown that ice generated area can be increased when using the thin layer ring structure during the same charging period, since energy can be transferred from water to the cooled cylinder through the thin layer ring more efficiently. The novel thin layer ring is used as extended fin to induce energy from not completely cooled region to the cooled cylinder. The mechanism of enhanced heat transfer is illustrated in detailed in Xie's previous work [27]. In Fig.1, the cross-section of ice tank is shown on the left side [28] and the investigated rectangular area is on the right side [29]. The three- dimensions geometry of thin layer ring is shown in Fig. 2 from a construction point of view. However, this novel technology has not been analysed in details during the ice formation process, many different parameters could impact its performance on the solidification of water. Usually, the change in thermal conductivity of material would vary the rate of heat transfer. Meanwhile, the distance of transferring also affects conductive heat transfer within the transferring material. Because of the phase change occurring in an ITS system, it always happens firstly near

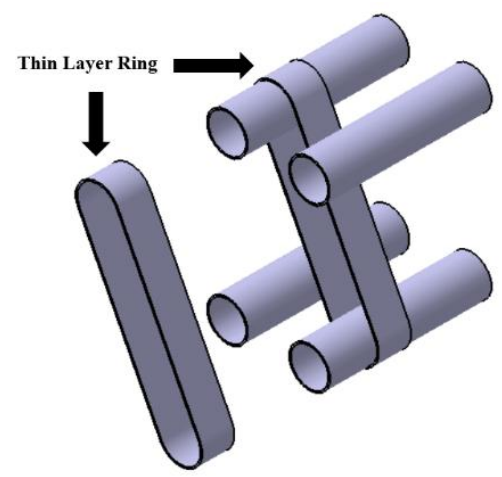

Fig. 2. Three dimensions thin layer ring attached on the surface of refrigerant tubes

the cooling source, the strategy or arrangement of transferring material also plays an important role, which needs to be taken into account.

The study focuses on the effect of material, thickness and arrangement of thin layer ring structure on the ice formation enhancement. It has been shown that the heat transfer performance of the thin layer ring is dependent on its material, thickness, and arrangement [27]. The ice formation with novel thin layer ring can be improved by increasing the thermal conductivity of a material. Copper, 
Aluminium and stainless steel were tested in our previous study [27]. Thickness effect was studied from $0.5 \mathrm{~mm}$ to $2 \mathrm{~mm}$, and the arrangement effect was investigated for the staggered arrangement and parallel arrangement. But these tests were limited by the number of factorial level.

In this study, the influence of various design parameters on the heat transfer enhancement with thin layer ring is analysed using numerical method in the rectangular space. The Taguchi method [30, 31, and 32] is introduced into this study. The method is used to demonstrate a systematic procedure of using Taguchi parameter design in product design of thin layer ring applied in ITS system. It is also adopted to demonstrate a use of the Taguchi parameter design in order to identify the optimum thin layer ring performance with a particular combination of parameters in the ITS system application.

\section{Numerical Simulation of Thin Layer Ring in ITS}

\subsection{Physical model}

In the study, the cooled cylinder in the fixed rectangular space is considered as the investigated area for this numerical study. The physical geometry of an ITS tank and the analysed rectangular space is shown in Fig.1. The cross section of an ITS tank is shown on the left of Fig.1. Many circular tubes represent the cross section of refrigerant cylinders. In the middle, the enlarged section shows the configuration of these refrigerant cylinders in details. During the solidification of water, water in the tank is nearly static and ice can be generated gradually from the outer surface of cylinders. Since both cylinder and water condition on one side are equivalent to the opposite side in the analysed space marked with red color, the boundary conditions on both red lines are equivalently axisymmetric. Therefore the rectangular area marked with red color can be representative to other areas with the same conditions in the ITS. For simplicity, this study is initially focused on the effect of thin layer ring on ice formation in the fixed rectangular area. The global impact has not been considered in this research in order to emphasize on such rectangular area and evaluate the impact of thin layer ring on ice formation. On the right side of Fig.1, it shows the position of investigated rectangular area in ice thermal

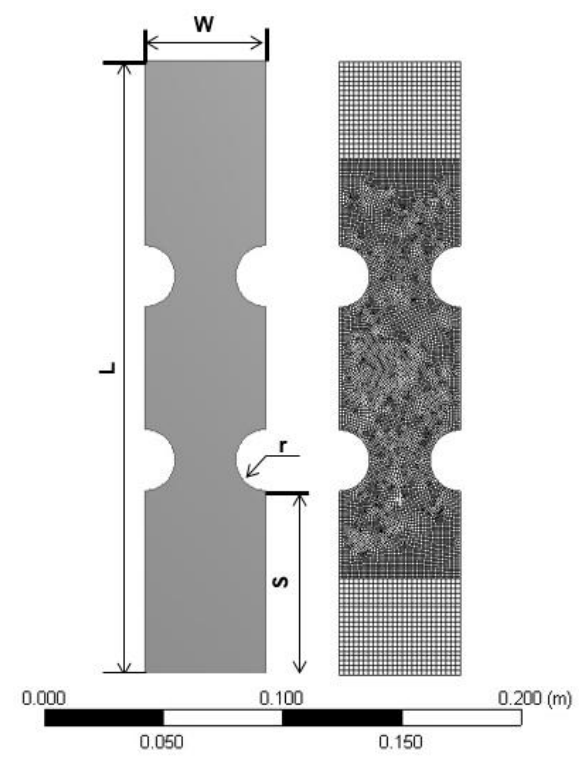

storage tank if compared with the left two. Two cylinders are shown in the right zoom area, but the rectangular area with four cylinders was taken into account for this study.

Table 1

Dimensions of analysed space

\begin{tabular}{ccccc}
\hline Parameter (unit) & $\mathrm{W}(\mathrm{m})$ & $\mathrm{L}(\mathrm{m})$ & $\mathrm{S}(\mathrm{m})$ & $\mathrm{r}(\mathrm{m})$ \\
\hline & 0.0508 & 0.254 & 0.0762 & 0.0127
\end{tabular}

\subsection{Numerical method and parameter definitions}

In Fig. 3, it shows the investigated area with dimensions. The diameter of the cylinder was set as $\mathrm{d}(\mathrm{d}=0.0254 \mathrm{~m})$, and the rectangular space heights (L) were taken as $7 \mathrm{~d}$ and $10 \mathrm{~d}$. The longitudinal and transverse spacing were both $2 \mathrm{~d}$ for this study. More detailed parameters of geometry are presented in Table 1.

The condition of transient natural convection was taken into the consideration of all numerical studies in the water with the cooled cylinder. The FLUENT program with a finite volume method was used to solve ice formation in fixed rectangular space as one and four cylinder geometries. An enthalpy formulation based approach was chosen within FLUENT in order to study the transport phenomena during solidification. The governing equations involved in numerical modelling are listed below.

\section{Continuity equation:}

$\frac{\partial \rho}{\partial t}=\nabla \cdot(\rho V)=0$

\section{Momentum equation:}

x-Momentum:

$\frac{\partial}{\partial t}(\rho u)+\nabla \cdot(\rho u V)=-\frac{\partial P}{\partial x}-\frac{\mu}{k} u+\nabla \cdot(\mu \nabla u)$

y-Momentum:

$\frac{\partial}{\partial t}(\rho v)+\nabla \cdot(\rho v V)=-\frac{\partial P}{\partial y}-\frac{\mu}{k} v+\nabla \cdot(\mu \nabla v)+\left(\rho_{m}-\rho\right) g$

\section{Energy equation:}

$\frac{\partial}{\partial t}(\rho h)+\nabla \cdot(\rho h V)=\nabla \cdot\left(\frac{k}{c} \nabla h\right)-\frac{\partial}{\partial t}(\rho \beta L)-\nabla(\rho \beta L V)$

Where $t$ is time; $\rho$ is density; $P$ is pressure; $V$ is velocity vector; $u$ and $v$ are velocity components in $\mathrm{x}$ and $\mathrm{y}$ directions; $\mu$ is dynamic viscosity; $\beta$ is liquid volume fraction; $L$ is latent heat.

For the mushy zone during phase changing, Darcy's law and the Kozeny-Carman equation were taken into consideration.

Kozeny-Carman equation:

$$
K=K_{0}\left(\frac{\beta^{3}}{(1-\beta)^{2}}\right)
$$

Sensible enthalpy-temperature relation, 


$$
h=\left\{\begin{array}{ll}
C_{s} T & T<T_{f} \\
C_{l} T & T \geq T_{f}
\end{array}\right\}
$$

Where $K_{0}$ is empirical constant in Kozeny-Carman equation shown above; $K$ is permeability; $\mathrm{T}_{\mathrm{f}}$ is fusion temperature; $C_{s}$ and $C_{l}$ are specific heats for solid and liquid phases, respectively.

In the energy equations shown above, sensible enthalpy, $\mathrm{h}$, is defined by the following equation.

$$
h=h_{\text {ref }}+\int_{T_{r f}}^{T} c d T
$$

Where, $h_{r e f}$ is reference enthalpy; $T_{r e f}$ is reference temperature; $\mathrm{c}$ is specific heat at constant pressure.

\subsection{Boundary conditions}

In the study, water in the investigated space was considered as Newtonian [33], incompressible, and laminar flow on account of simplicity.

Boundary Conditions: Since the investigated rectangular space is horizontally symmetrical to the neighbouring space and in order to see the effect of thin layer ring with four cylinders, heat transfer in the vertical direction through the top and bottom walls was not taken into account. The global natural convection from the outside of investigated rectangular area in the vertical direction is neglected. During the solidification of water, water in the tank is nearly static. The following assumptions are made for the boundary conditions: (1) symmetry condition at the left and right boundaries, except cylinder surfaces; (2) Adiabatic and no-slip conditions at top and bottom walls; (3) $h=h_{w}=$ $C_{s} T_{w}$ and $u=v=0$ at cylinder surfaces; (4) Perfect contact on cylinders.

Initial conditions: Since the refrigerant temperature inside cylinder is much colder than the temperature of water in the investigated space, the following assumptions were made for the initial conditions: (1) Water is at rest at $\mathrm{t}$ $=0$; (2) $h=h_{i}=C_{l} T_{i}$ at $t=0$; (3) $t_{c}=263.15 \mathrm{~K}$ (temperature on the cylinder surface); (4) $t_{w}=277.15 \mathrm{~K}$ (temperature of water).

Table 2

Thermo-physical properties of water in the study

\begin{tabular}{cccc}
\hline Property & Specification & Property & Specification \\
\hline$\rho_{\mathrm{f}}$ & 999.833 & $\mu$ & $0.5712-0.005705 \mathrm{~T}+1.91 \times 10^{-}$ \\
& $\mathrm{kg} / \mathrm{m}^{3}$ & & ${ }^{2} \mathrm{~T}^{2}-2.141 \times 10^{-8} \mathrm{~T}^{3} \mathrm{~kg} / \mathrm{m}-\mathrm{s}$ \\
$\mathrm{c}_{\mathrm{s}}$ & $2,217 \mathrm{j} / \mathrm{kg}-\mathrm{k}$ & $\mu_{\mathrm{f}}$ & $0.00162 \mathrm{~kg} / \mathrm{m}-\mathrm{s}$ \\
$\mathrm{c}_{\mathrm{l}}$ & $4,180 \mathrm{j} / \mathrm{kg}-\mathrm{k}$ & $\mathrm{L}$ & $334,000 \mathrm{j} / \mathrm{kg}$ \\
$\mathrm{K}_{\mathrm{s}}$ & $1.918 \mathrm{~m}^{2}$ & $\mathrm{~T}_{\mathrm{f}}$ & $273.15 \mathrm{~K}$ \\
$\mathrm{~K}_{\mathrm{l}}$ & $0.578 \mathrm{~m}^{2}$ & $\mathrm{~K}_{0}$ & $10^{-8} \mathrm{~m}^{2}$ \\
\hline
\end{tabular}

\subsection{Solution method and model validation}

A quadrilateral grid was adopted for the simulation, and a refined grid distribution was applied near cylinder surfaces for the accuracy of the numerical solution. The refined grid is shown in Fig. 3. Therefore, the region around the location where the cylinder was placed had a higher resolution, which can increase the accuracy of simulation around the cylinder surfaces.

SIMPLEC algorithm was used to solve the equations presented in the previous section, while the governing equations for momentum and energy were discretized with the finite volume formulation using the QUICK scheme. The gradient was based on Green-Gauss. Considering the control of the convergence of solution, the under-relaxation factors were set as 0.3 and 0.7 , respectively. The residuals of continuity, momentum, and energy equations were set to be less than $1 \times 10^{-4}, 1 \times 10^{-3}$ and $1 \times 10^{-8}$, respectively. Based on the solution method described above, the iteration continued until the computation converged and became stable.

In the grid independence validation, the parameters of investigated rectangular area and numerical model were fixed, so the only variable is grid number. Since it is a 2-D analysis with simple geometry containing static water, the validation of the solution of the grid number was addressed to test four different grid numbers in $3,923,15,668,24,520$ and 35,425 , respectively. In the validation, the parameters of rectangular area and numerical model were fixed. The ratio of $\mathrm{Ai} / \mathrm{Ac}$ at 900 seconds along the solidification process with different grid number is shown in Fig. 4. It can be seen that the ratio of $\mathrm{Ai} / \mathrm{Ac}$ does not vary greatly and nearly remains a constant value (difference less than $5 \%$ ) when the grid number is higher than 24,520 . To ensure the accuracy of the computational solution, the grid number was created as large as 24,520 due to the approaching similarity of the numerical values.

Validation of this numerical method has been conducted [29]. The results shows that the numerical data matches well with the experimental data in entire time range. From

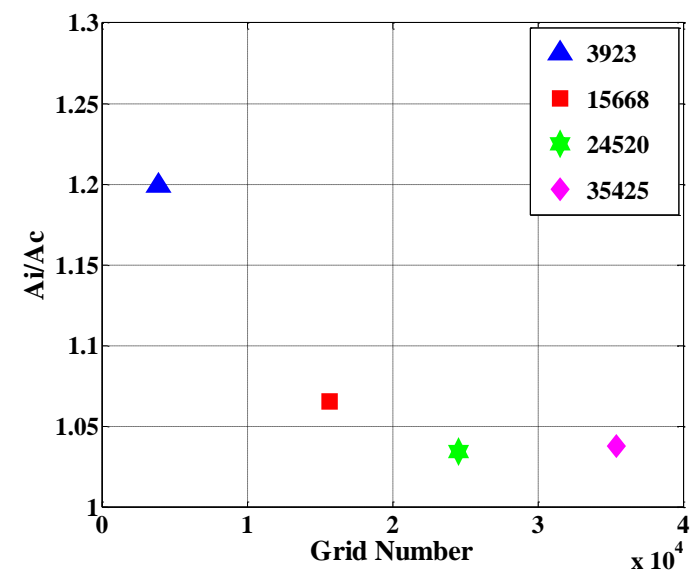

Fig. 4. Ratio of $A_{i} / A_{c}$ with different grid number at 900s [14]

the promising validation results, the numerical method adopted in this study is valid and can be used for ice formation with complicated scenarios.

\subsection{Factorial effect analysis}


Using the thin layer ring in the ice storage tank has been proved effective from the previous computational results [12], since the time of the ice formation can be shortened and the area ratio can be increased. In other words, the overall efficiency of ice thermal storage system can be improved. However, there is a large arrangement space as well as different placement strategies which need to be investigated for the utilization of a thin layer ring for the improvement of an ice thermal storage system. This is to say, many unknown parameters and different arrangements should be explored and determined on their variations in details. For this reason, material, thickness, and different placements were investigated initially for the thin layer ring structure. The baseline shown in Table 3 with three constant parameters was used to compare with different cases using different parameters and values. The parameters with different values in the following studies are shown in Table 4.

Table 3

Baseline of thin layer ring

\begin{tabular}{ccc}
\hline Material & Thickness & Arrangement \\
\hline Aluminium & 1 & Staggered \\
\hline
\end{tabular}

Table 4

Investigated parameters

\begin{tabular}{cccccc}
\hline Parameter & \multicolumn{3}{c}{ Value } \\
\hline Material & Aluminium & Copper & $\begin{array}{c}\text { Stainless } \\
\text { Steel }\end{array}$ & $\begin{array}{c}\text { Magnesium } \\
\text { Alloy }\end{array}$ & - \\
$\begin{array}{c}\text { Thickness } \\
(\mathrm{mm})\end{array}$ & 0.25 & 0.5 & 1 & 2 & 3 \\
Arrangement & Staggered & Parallel & - & - & -
\end{tabular}

\subsubsection{Effect of material}

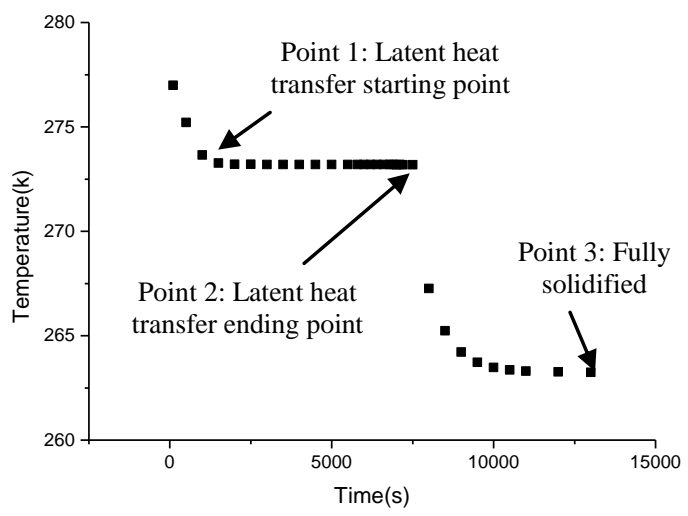

Fig. 5. Time-wise temperature during ice formation

Heat transfer materials in industrial application are usually aluminium, copper, and stainless steel. Moreover, magnesium alloy has recently been applied to high-tech field as heat transfer material with light weight and better metal performance. In general, stainless steel has the lowest thermal conductivity among these four, while aluminium is slightly higher than magnesium alloy. Copper has the best heat transfer performance among the four materials. In this study, these four materials were chosen for the thin layer ring, while the other parameters were kept the same. To better understand the effect of these materials on ice formation process in the middle along with time, the temperature at the center point of investigated domain was monitored during the studies.

In Fig. 5, it shows the time-wise temperature change for the case without thin layer ring. It can be seen temperature drops from the initial point at $277.15 \mathrm{~K}$ and then reaches the lower limit of the phase transition point which is latent heat transfer starting point 1 . After point 1 , temperature during phase change remains constant. At point 2 , that is latent heat transfer ending point, the energy required to accomplish the phase change has transferred completely. Then the temperature continues to drop to the point 3 which is refrigerant temperature at $263.15 \mathrm{~K}$. Therefore, for the material study, the temperature at the center of the rectangular domain took nearly 500 seconds to reach the lower limit of the phase transition temperature (freezing point) for the copper case, 800 seconds for the aluminium case, 800 seconds for magnesium alloy case, 1600 seconds for the stainless steel case and 2000 seconds for the case without the ring. The time-wise results of material are concluded in Table 5. The points in Table 5. can be obviously found in Fig. 5. After that, the temperature at the center point in five different cases remained constant during the phase transition of water from liquid to solid. At the start of the phase transition, heat transfer was primarily dominated by convection within the water region and by conduction after the water turned into ice. This occurred because during ice formation, the rate at which energy was absorbed from the refrigerant cylinder balanced the rate at which energy was transferred to the adjacent phase changing material as a result of the temperature gradient in the rectangular region. The latent heat transfer time is between 500 seconds to 1500 seconds in the copper case, between 800 seconds to 2200 seconds in the aluminium case, between 800 seconds to 3800 seconds in the magnesium alloy case, between 1600 seconds to 6200 seconds in the stainless steel case, between 2000 to 7500 seconds in the no ring case. A rapid drop of the phase transition temperature occurred from 7500 seconds in the case without the ring at the start of the sensible heat transfer process and continued changing until the temperature was close to the refrigerant temperature of $263.15 \mathrm{~K}$ at 130000 seconds. A similar process also occurred from 6200 seconds to 9000 seconds in the stainless steel case, from 2200 to 4500 seconds in the aluminium case, from 3800 seconds to 7500 seconds in the magnesium alloy case, from 1500 seconds to 2800 seconds in the copper case.

Table 5

Time-wise results of material study

\begin{tabular}{cccc}
\hline Material & Point 1 (S) & Point 2 (S) & Point3 (S) \\
\hline Aluminium & 800 & 2200 & 4500 \\
Copper & 500 & 1500 & 2800 \\
Stainless Steel & 1600 & 6200 & 9000
\end{tabular}




\begin{tabular}{cccc} 
Magnesium Alloy & 800 & 3800 & 7500 \\
Without Ring & 2000 & 7500 & 13000 \\
\hline
\end{tabular}

\subsubsection{Effect of thickness}

Typically, with the increase in thickness, the thermal resistance will also increase, while the heat transfer rate will decrease due to the thermal conduction distance. In this study, the thicknesses of thin layer ring are evaluated at $0.25 \mathrm{~mm}, 0.5 \mathrm{~mm}, 1 \mathrm{~mm}$ and $2 \mathrm{~mm}, 3 \mathrm{~mm}$, while the other parameters are kept the same as the base line.

The conclusion of thickness study in Table 6 shows the temperature at the center point took nearly 800 seconds to reach the lower limit of the phase transition temperature for the five cases with thin layer ring. However, it took 2000 seconds for the case without the ring. The points in Table 6. can be obviously found in Fig. 5. After that, the temperature at the center point in 6 different cases remains constant during the phase transition of water from liquid to solid. At the start of the phase transition, heat transfer was primarily by convection within the water region and by conduction after water turns into ice. This is because during ice formation, the rate at which energy was absorbed from the refrigerant cylinder balanced the rate at which energy was transferred to the adjacent phase changing material, as a result of the temperature gradient in the rectangular region. The latent heat transfer time is between 800 seconds to 5200 seconds in the $0.25 \mathrm{~mm}$ aluminium case, between 800 seconds to 4100 seconds in the $0.5 \mathrm{~mm}$ case, between 800 seconds to 2200 seconds in the $1 \mathrm{~mm}$ case, between 800 seconds to 2400 seconds in $2 \mathrm{~mm}$ case, between 800 seconds to 1900 seconds in the $3 \mathrm{~mm}$ case and between 2000 to 7500 seconds in the none wing case. An interesting phenomenon was observed, the thinnest case with $0.25 \mathrm{~mm}$ ring took longer than other four thicknesses from 800 seconds to 5200 seconds during the latent heat transfer process, since the ring is too thin to absorb heat from the water and to transfer the heat to refrigerant cylinder through conduction. A rapid drop of the phase transition temperature occurred from 7500 seconds in the case without the ring at the start of the sensible heat transfer process and continued changing until the temperature was close to the refrigerant temperature of $263.15 \mathrm{~K}$ at 130000 seconds. This similar process also occurred from 5200 seconds to 6300 seconds in the $0.25 \mathrm{~mm}$ case, from 4100 seconds to 6500 seconds in the $0.5 \mathrm{~mm}$ case, from 2200 seconds to 4500 seconds in the $1 \mathrm{~mm}$ case, from 2400 seconds to 3500 seconds in the $2 \mathrm{~mm}$ case, from 1900 to 3000 seconds in the $3 \mathrm{~mm}$ case.

Table 6

Time-wise results of thickness study

\begin{tabular}{cccc}
\hline Thickness & Point 1 (S) & Point 2 (S) & Point3 (S) \\
\hline $0.25 \mathrm{~mm}$ & 800 & 5200 & 6300 \\
$0.5 \mathrm{~mm}$ & 800 & 4100 & 6500 \\
$1 \mathrm{~mm}$ & 800 & 2200 & 4500 \\
$2 \mathrm{~mm}$ & 800 & 2400 & 3500 \\
$3 \mathrm{~mm}$ & 800 & 1900 & 3000
\end{tabular}
Without Ring
2000
7500
13000

\subsubsection{Effect of arrangement}

Changing in the arrangement of thin layer ring will result in variation of heat transfer area, which would change heat transfer rate. Therefore, three different arrangements are analysed in this study to investigate the effect of arrangement shown in Fig. 6: staggered, 1 parallel, and 2 parallel scenarios, while the other parameters, such as material and thickness are kept the same as the base line. For the staggered arrangement, the thin layer ring is deployed across the center area. For the 1 and 2 parallel arrangement, the thin layer ring is attached to two neighbouring cooled cylinders.

After running simulations, it can be depicted that the temperature at the center point, shown in Table 7 took nearly 800 seconds to reach the lower limit of the phase transition temperature for the staggered case, the 1 parallel case, and the 2 parallel case. However, it took 2000 seconds for the case without the ring. The points in Table 7. can be obviously found in Fig. 5. After that, the temperature at the center point in 4 different cases remains constant during the phase transition of water from liquid to solid. The latent heat transfer region is between 800 seconds to 2200 seconds in the staggered case, between 800 seconds to 5500 seconds in 1 parallel case, between 800 seconds to 5000 seconds in 2 parallel case and between 2000 to 7500 seconds in the none wing case. The result of this process is well predicted, since 2 parallel case has increased heat transfer area. The latent heat transfer rate is greater than 1 parallel case. A rapid drop of the phase transition temperature occurred from 7500 seconds in the case without the ring at the start of the sensible heat transfer process and continued changing until temperature is close to the refrigerant temperature of $263.15 \mathrm{~K}$ at 130000 seconds. This similar process also occurred from 2200 to 4500 seconds in the staggered case, from 5500 seconds to 9000 seconds in the 1 parallel case, from 5000 seconds to 8000 seconds in the 2 parallel case.

Table 7

Time-wise results of arrangement study

\begin{tabular}{cccc}
\hline Arrangement & Point 1 (S) & Point 2 (S) & Point3 (S) \\
\hline 1 Staggered & 800 & 2200 & 4500 \\
1 Parallel & 800 & 5500 & 9000 \\
2 Parallel & 800 & 5000 & 8000 \\
Without Ring & 2000 & 7500 & 13000 \\
\hline
\end{tabular}

\section{Parametric study by Taguchi Method}

In the previous section, thin layer ring has been numerically investigated on its material, thickness and arrangement systematically. From the results, it shows increasing thermal conductivity and area of thin layer ring can shorten ice formation period, while ice formation period is also dependent on the thickness of thin layer ring. There is an optimal thickness for thin layer ring. However, 
for this new structure, these three parameters need to be further numerically investigated with the statistic method to predict the optimal condition of each parameter to enhance the performance of thin layer ring in the real world, since experiments on its performance without comprehensive numerical investigation will be very time consuming and will inevitably increase the cost of study [34]. Here the Taguchi method is adopted to numerically evaluate the performance of thin layer ring for thermal enhancement in ITS system statistically and comprehensively.

The Taguchi method is a methodology for the application of designed experiments. It is developed by Dr. Taguchi, the "father of robust design". His method can make experiment simpler by using fewer experimental designs and providing a better understanding of the variations of system [35, 36]. The method advocates a three-stage design methodology for [36]:

1. Designing products/processes so as to be robust to environmental conditions;

2. Designing and developing products/processes so as to be robust to component variation;

3. Minimizing variation around a target value;

Many optimal robust designs of a product or process have been investigated with Taguchi method [37] and [38]. His optimization method can be characterized as a threestep approach, which includes system design, parameter design, and tolerance design.

In system design, it contains product design and relative process design. As discussed in product design, it includes the selection of materials, components, tentative product parameter values, etc. In parameter design, it is used to optimize the characters of the product parameter values.
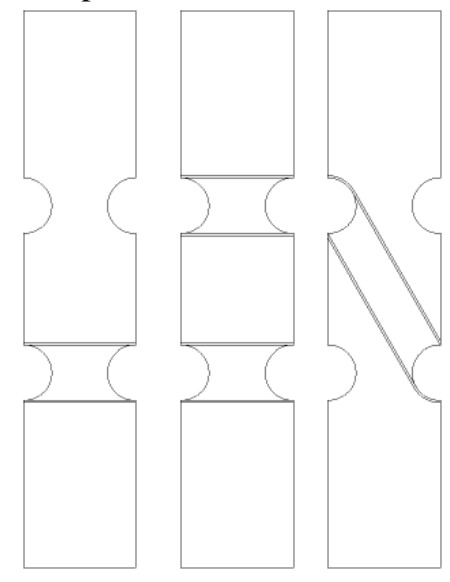

1 Parallel

2 Parallel Staggered

Fig. 6. Three arrangements of thin layer ring

The optimal product parameter values obtained from the parameter design are not sensitive to the variation of environmental conditions and other noise factors. Therefore the parameter design is the most important step among three steps of the Taguchi method. In fact, Fisher [39] developed the classical parameter design that is complex and cannot be easily used. When the number of product parameters increases, a large number of experiments should have to be carried out. However, the Taguchi method contains a special design of orthogonal arrays to analyse the entire parameter space with a small number of experiments.

Usually, the parameter design of Taguchi method to find the optimal combination of product contains the following steps [40], each step will be presented in details for the parametric study of thin layer ring later:

- Identify the performance characteristics and select product parameters to be evaluated.

- Determine the number of levels for the process parameters and possible interactions between product parameters.

- Select the appropriate orthogonal array an assignment of product parameters to the orthogonal array.

- Conduct the experiments based on the arrangement of the orthogonal array.

- Calculate the $\mathrm{S} / \mathrm{N}$ ratio.

- Analyse the experimental results using the $\mathrm{S} / \mathrm{N}$ ratio.

- $\quad$ Select the optimal levels of process parameters.

- Verify the optimal process parameters through the confirmation experiment.

\subsection{Selection of characteristics}

In general, heat transfer enhancement in ITS system results in increasing the ice generated area during the same time period and shortening ice formation time. Therefore, a new parameter is defined to evaluate increased ice area for the Taguchi analysis. Usually, there are three categories of the performance characteristic in the analysis, which are the smaller-the-better, the larger-the-better and the nominalthe-better. In this study, IA factor introduced in this study stands for increased ice formation area during the same period. IA factor is also a number of larger-the-better characteristics showing the percentage of the increased ice generated area compared to the case without thin layer ring, and is defined as follows.

$$
I A=\frac{A_{T L R @ \text { SamePeriod }}-A_{\text {bare@ SamePeriod }}}{A_{\text {bare@ SamePeriod }}} \times 100
$$

Where, $\mathrm{A}_{\text {TLR@SamePeriod }}$ is area generated by thin layer ring during the same period as bare case, and $\mathrm{A}_{\text {bare@SamePeriod }}$ is area generated without thin layer ring during the same period as thin layer ring case.

\subsection{Factor and levels}

In the Taguchi analysis, the control factors and their levels are firstly defined. The significance of different parameters, such as material, thickness, arrangement investigated will be addressed. Base on the above study on the effectiveness of three parameters, the levels of each factor in this study are shown in Table 8 in order to perform the comparison study of each parameter.

Table 8

Levels of each factor

\begin{tabular}{lllll}
\hline Code & Factors(unit) & Level 1 & Level 2 & Level 3 \\
\hline A & Material & Aluminium & Stainless & Copper
\end{tabular}




\begin{tabular}{lllll}
\hline & & \multicolumn{3}{c}{ Steel } \\
B & Thickness (mm) & 0.5 & 1.0 & 2.0 \\
C & Arrangement & Staggered & $\begin{array}{l}\text { One } \\
\text { parallel }\end{array}$ & $\begin{array}{l}\text { Two } \\
\text { Parallel }\end{array}$ \\
\hline
\end{tabular}

\subsection{Orthogonal array}

According to the numerical database analysed above, an orthogonal array of $\mathrm{L}_{9}(3 \times 3)$ is designed for study as shown below in Table 9.

\begin{tabular}{cccc}
$\begin{array}{l}\text { Table } 9 \\
\text { The orthogonal array of } \mathrm{L}_{9}\end{array}$ & A & B & C \\
\hline Number of test & A & 1 & 1 \\
\hline Test 1 & 1 & 2 & 2 \\
Test 2 & 1 & 3 & 3 \\
Test 3 & 2 & 1 & 2 \\
Test 4 & 2 & 2 & 3 \\
Test 5 & 2 & 3 & 1 \\
Test 6 & 3 & 1 & 3 \\
Test 7 & 3 & 2 & 1 \\
Test 8 & 3 & 3 & 2 \\
Test 9 & &
\end{tabular}

\subsection{SN analysis}

In the quality engineering and experimental design, the SN ratio (signal to noise ratio) was firstly introduced by Taguchi and has also been widely used. The SN ratio is calculated from the following equation. After the analysis of the SN ratio, the main effective factors could be determined, and the interaction of each parameter could be more clearly understood. Considering the characteristics of the subject, the larger the better scenario is taken into consideration in the study.

$$
S N(=\eta)=-10 \log \left[\frac{1}{I A^{2}}\right]
$$

\subsection{Taguchi Analysis}

\begin{tabular}{cccccc}
$\begin{array}{l}\text { Table } 10 \\
\text { SN ratio on each case }\end{array}$ & & & & \\
\hline $\begin{array}{c}\text { Number of } \\
\text { test }\end{array}$ & A & B & C & IA & $\begin{array}{c}\text { SN } \\
\text { Ratio( } \eta)\end{array}$ \\
\hline Test 1 & 1 & 1 & 1 & 21.7943 & 26.7668 \\
Test 2 & 1 & 2 & 2 & 11.4942 & 21.2096 \\
Test 3 & 1 & 3 & 3 & 13.4051 & 22.5454 \\
Test 4 & 2 & 1 & 2 & 3.3247 & 10.4350 \\
Test 5 & 2 & 2 & 3 & 8.9204 & 19.0077 \\
Test 6 & 2 & 3 & 1 & 7.8325 & 17.8781 \\
Test 7 & 3 & 1 & 3 & 23.4918 & 27.4183 \\
Test 8 & 3 & 2 & 1 & 27.9337 & 28.9226 \\
Test 9 & 3 & 3 & 2 & 14.6284 & 23.3040 \\
\hline
\end{tabular}

The SN ratio calculated from the nine numerical simulations is presented above in Table 10. With the SN ratio obtained, the contribution ratio of every factor can be calculated and shown in the Table 11. In the Table 11, the $\Delta$ is the difference between the maximum and minimum of the SN ratio for each factor. After adding up all the $\Delta$ of each factor, the total $\Delta$ is equal to 18.78. After that, to evaluate the influence of each factor on the percentage of increased ice area (IA), the contribution ratio is then introduced. The contribution ratio equals to the value of the $\Delta$ of each factor divided by the total $\Delta$ of all factors. Therefore, the main effective factors could be determined. By the calculation, the contribution ratio of each factor can be obtained as follows: $57.35 \%$ for material, $9.58 \%$ for thickness, $33.07 \%$ for arrangement. It can be obviously seen in Fig. 7. That means material has the most impact on the percentage of increased ice area when using thin layer ring structure, while other factors have relatively less influence on ice generated area. Based on these results, in the design process, material should be given more considerations. Next is the arrangement of thin layer ring. Finally, thickness is the third factor to be considered.

The above analyses on the contribution ratio are limited to evaluating the significance of these three factors only. To determine the optimal design, the SN ratio of each factor should be taken into further consideration. From the Fig. 8, the largest $\mathrm{SN}$ ratio among the 3 levels stands for the best performance when using the Taguchi method for the experimental design. Fig. 8 shows the results below. For the factor A (material), level 3 (Copper) is the best. Level 2

Table 11

Factorial effect and contribution ratio

\begin{tabular}{ccccc}
\hline & Level & A & B & C \\
\hline SN ratio & 1 & 23.51 & 21.54 & 24.52 \\
& 2 & 15.77 & 23.05 & 18.32 \\
& 3 & 26.55 & 21.24 & 22.99 \\
\hline$\Delta$ & 18.78 & 10.77 & 1.80 & 6.21 \\
(Max-Min) & & & & \\
Contribution & $100 \%$ & $57.35 \%$ & $9.58 \%$ & $33.07 \%$ \\
ratio (\%) & & 1 & 3 & 2 \\
Rank & & & &
\end{tabular}

$(1 \mathrm{~mm})$ is the best for the factor B (thickness). For the factor $\mathrm{C}$ (arrangement), level 1 (staggered) is the best. However, the factor B has insignificant effect on ice generation area. From the results presented above, material, thickness, arrangement have the optimal condition when set as copper, $1 \mathrm{~mm}$, staggered, respectively. 


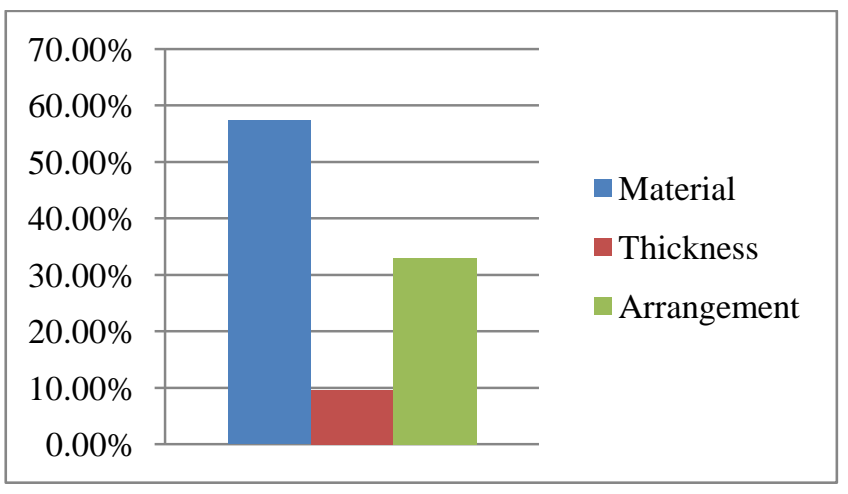

Fig. 7. Contribution ratio on each factor

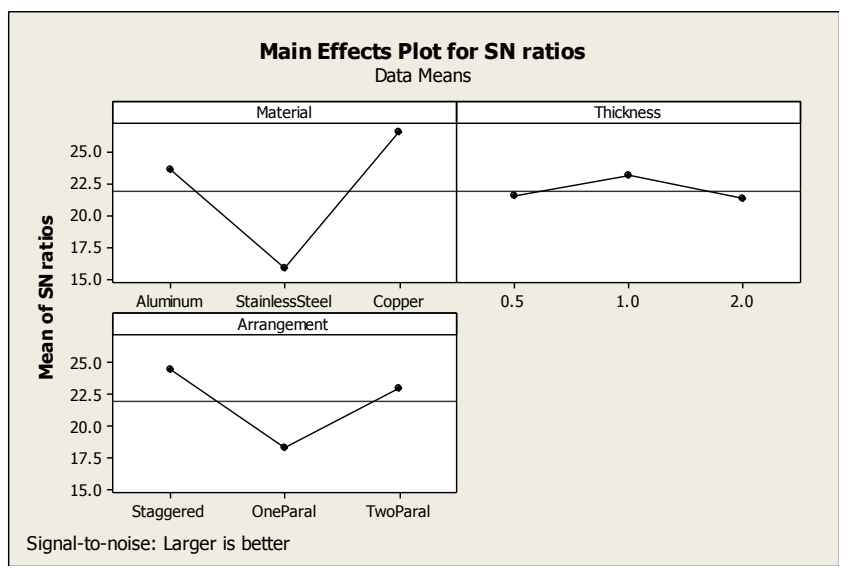

Fig. 8. SN ratio on each factor

\subsection{Determination of the optimal condition}

After running Taguchi method, the optimal condition can be obtained by a combination of levels presenting the largest SN ratio in each control factor as shown in Table 11. As a result, two optimal conditions are selected in this study as shown in Table 12. However, in reality, only one optimal condition can be obtained using the present method, but the second optimal condition is also taken into consideration for the confirmation test. Therefore, one original optimal condition is determined based on the Taguchi analysis method, and the second optimal condition is selected to eliminate the error of analysis and find the best condition. These two optimal conditions are A3B2C1 and $\mathrm{A} 1 \mathrm{~B} 1 \mathrm{C} 3$, respectively.

\subsection{Reproducibility by confirmation test}

The two test samples combined with the three factors were designed and selected to be the optimal conditions as described above for the confirmation test. These two conditions and factors are shown in Table 12. Two methods were adopted into the confirmation test.

Table 12

Optimal conditions from factorial effect analysis

\begin{tabular}{ccc}
\hline \multicolumn{2}{l}{ Optimal conditions from factorial effect analysis } & \\
\hline Optimal Condition & Condition 1 & Condition 2 \\
\hline Material & Copper & Aluminium
\end{tabular}

$\begin{array}{ccc}\text { Thickness } & 1 \mathrm{~mm} & 0.5 \mathrm{~mm} \\ \text { Arrangement } & \text { Staggered } & \text { 2 Parallel }\end{array}$

The first method was to compare the presumed SN ratio for the optimal condition and the $\mathrm{SN}$ ratio of confirmation test results for the optimal samples. $\eta_{\text {pre }}$ is the presumed SN ratio calculated based on the following equation.

$\eta_{\text {pre }}=\eta_{A 3}+\eta_{B 2}+\eta_{C 1}-2 \times \bar{\eta}$

$\eta_{\text {pre }}=26.55+23.05+24.52-2 \times 21.94=30.24$

In the above equation, values were selected as the largest SN ratio for each factor and taken from Table 11. $\bar{\eta}$ is taken as the average value of nine $\mathrm{S} / \mathrm{N}$ ratio in Table 11. Therefore the predsumed $\eta_{\text {pre }}$ was 30.24 . However, the SN

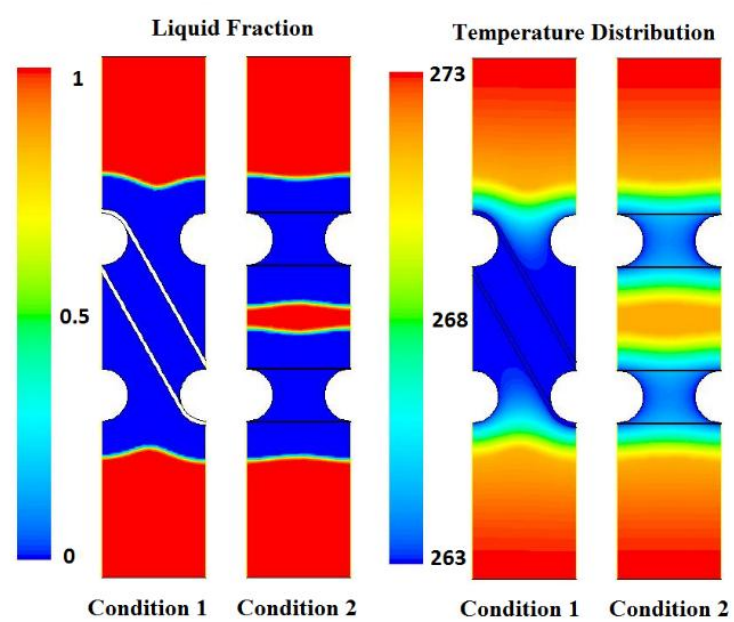

Fig. 10. Liquid fraction and temperature distribution of condition 1 and condition 2 at 3600 seconds

ratio of the optimal Condition 1 was directly obtained from Table 10, which is 28.9226. Since the presumed $\eta_{\text {pre }}$ is greater than that of Condition 1 and they are very close to each other, that is to say the existence of reproducibility in this condition is confirmed.

Hence, the second method is to confirm the reproducibility by comparing IA factor of Condition 1 and Condition 2. From the previous analysis, IA factor of Condition 1 is directly obtained from Table 10, which is 27.93. The result from the simulation of Condition 2 showed IA factor of Condition 2 is 11.6. The IA factor of the optimal Condition 2 is lower than that of the optimal

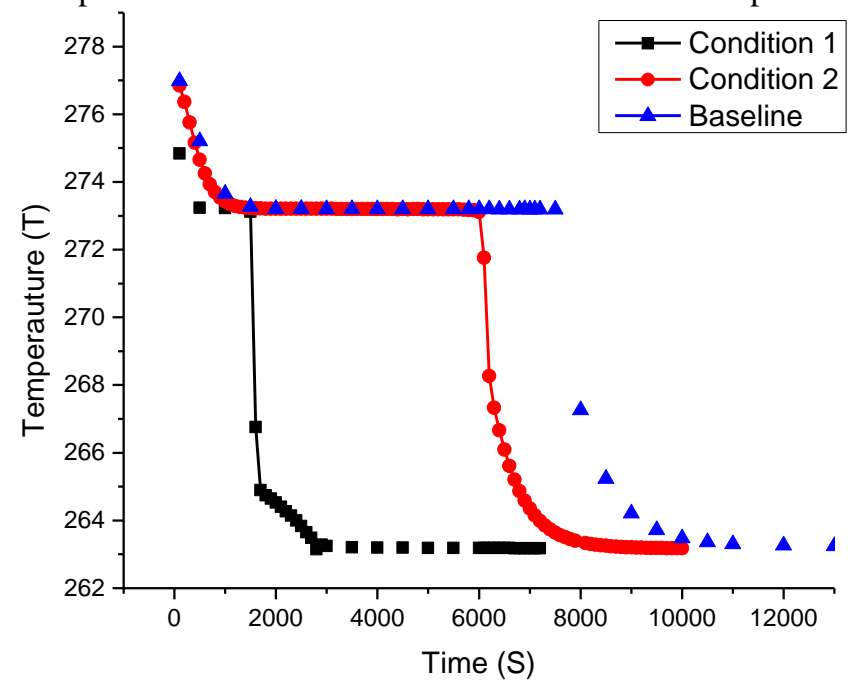

Fig. 9. Time-wise temperature during ice formation 
Condition 1 and there is no interaction between three parameters. Therefore, it is demonstrated that the optimal Condition 1 performs better than the optimal Condition 2 and all others. That is to say it is the ultimate combination of thin layer ring's three parameters.

In Fig. 9, it shows the time-wise temperature change for the condition 1 , condition 2 and the baseline. For the condition 1, the temperature drops before 2000 seconds and then reaches the lower limit of the phase transition point which is latent heat transfer starting point. However, the condition 2 takes longer than condition 1. Moreover, the baseline forms ice longest among all combinations including the condition 1 and condition 2. Fig. 10 shows the liquid fraction and temperature distribution of the analyzed domain for the condition 1 and condition at 3600 seconds. It is obvious that ice is generated more by condition 1 than condition 2 in the figure showing liquid fraction, in which 1 indicates the liquid state and 0 indicates the solid state. In the figure of temperature distribution, the area of condition 1 shows much colder than condition 2 , since it has better heat transfer combination of three parameters of thin layer ring.

\section{Conclusions}

In this study, the impact of the different parameters of thin layer ring on ice formation in a rectangular space has been evaluated and investigated by the numerical method. Moreover, the optimal parameters and condition have been determined by the Taguchi method. The numerical results from this study can be used as a research guideline of the novel structure of thin layer ring applied in ice thermal storage tank for other researchers in their experiments. The main results of this study are concluded as follows:

1 The comparative study of different parameters, such as material, thickness and arrangement have been conducted. From the results, it is shown that ice formation period can be shortened with the increase of conductivity and area of thin layer ring, while it is also dependent on thickness.

2 The factorial impact of the different parameters of thin layer ring during ice formation using numerical methods has been evaluated. The results show that material has the greatest impact on ice increased area. After that, arrangement has relatively less influence on ice increased area. However, thickness has the trifling effect on ice increased area.

3 From the study, the optimal combination of each factor (parameter) has been determined, and the optimal condition is A3B2C1. The reproducibility of these conditions has been verified by two analytical results.

\section{Acknowledgement}

This study is financially supported by the U.S. Department of Energy's Industrial Assessment Center (DEEE 0005537) at the University of WisconsinMilwaukee.

\section{References}

[1] H. Caliskan, I. Dincer, and A. Hepbasli, Energy and exergy analyses of combined thermochemical and sensible thermal energy storage systems for building heating applications. Energy and Buildings, 48(0): p. 103-111, 2012

[2] R. Saidur, H.H. Masjuki, M.Y. Jamaluddin, An application of energy and exergy analysis in residential sector of Malaysia, Energy Policy.

[3] Salvador, M. and S. Grieu, Methodology for the design of energy production and storage systems in buildings: Minimization of the energy impact on the electricity grid. Energy and Buildings, 47(0): p. 659-673, 2012.

[4] C.F. Shears, Australian Refrigeration, Air conditioning and Heating, AIRAH, Melbourne, Australia, 1991.

[5] D.T. Redindel, in: Proc. On EPRI Intl. Conf. on Sustainable Thermal Energy Storage, Minnesota, USA, 1996.

[6] S.M. Hasnain, N.M. Alabbadi, H.A. Aboud and Y.G. Al-Harbi, in: Proc. Workshop on Electrical Energy Conservation and Load Management, King Abdulaziz City for science and Technology (KACST), Riyadh, Saudi Arabia, p. 144, 1997.

[7] B. Rismanchi, R. Saidur, H. H. Masjuki and T. M. I. Mahlia, Thermodynamic evaluation of utilizing different ice thermal energy storage systems for cooling application in office buildings in Malaysia, Energy and Building, 53, 117-126, 2012.

[8] H. Akbari and A. Mertol, in: Energy Storage System: Fundamentals\&Application, ed. B. Kilkis, and S. Kakac. Kulwer Academic Publishers, 1989.

[9] R.S. Sumpter, Energy Engineering, 89(4), 1992.

[10]M. Brower, Cool Energy, Massachusetts Institute of Technology Press, USA, Revised Edition, 1994.

[11]C. Chaichana, W.W.S. Charters, and L. Aye, An ice thermal storage computer model. Applied Thermal Engineering, 21(17): p. 1769$1778,2001$.

[12]T. Collins, S.A. Parker, D. Brown, Thermal Energy Storage for Space Cooling, in: Technical report produced for the U.S. Department of Energy, Pacific Northwest National Laboratory, 2000.

[13]M. D. Haughey, Ice thermal storage for Colorado school, ASHRAE, 45, pp. 50-53, 2003.

[14]S. Morgan, M. Krati, Field testing of optimal controls of passive and active thermal storage, ASHRAE, 116, pp. 134-146, 2010.

[15] Habeebullah, B.A., Economic feasibility of thermal energy storage systems. Energy and Buildings, 39(3): p. 355-363, 2007.

[16]M.M. MacCracken, Thermal Energy Storage MYTHS, ASHRAE Journal 45, 36-42, 2003.

[17]Tabors Caramanis \& Associates, Source Energy and Environmental Impacts of Thermal Energy Storage, California Energy Commission, Report No 500-95-005, CA, USA, 1996.

[18] ASHRAE Handbook, HVAC Applications, 2007

[19]M. Yamaha, N. Nakahara, and R. Chiba, Studies on thermal characteristics of ice thermal storage tank and a methodology for estimation of tank efficiency. International Journal of Energy Research, 32(3): p. 226-241, 2008.

[20]J.N.-W. Chiu, V. Marthin, F. Setterwall, A review of thermal energy storage systems with salt hydrate phase change materials for comfort cooling, in: Proceedings of EFFSTOCK 2009, 11th International Conference on Thermal Energy Storage, Stockholm, Sweden, 2009.

[21]E.M. Sparrow, E.D. Larsen, J.W. Ramsey, Freezing on a finned tube 
for either conduction-controlled or natural-convection-controlled heat transfer, Int. J. Heat Mass Transfer 24, 273-284, 1984.

[22] M. Lacroix, Study of the heat transfer behavior of a latent heat thermal energy storage unit with a finned tube, Int. J. Heat Mass Transfer 36, 2083-2092, 1993.

[23] P.V. Padmanabhan and M.V. Krishna Murthy, Outward phase change in a cylindrical annulus with axial fins on the inner tube, Int. J. Heat Mass Transfer 29, 1855-1866, 1986.

[24]R. Siegel, Solidification of low conductivity material containing dispersed high conductivity particles, Int. J. Heat Mass Transfer 20, 1087-1089, 1997.

[25]C.J. Hoogendoorn, G.C.J. Bart, Performance and modeling of latent heat store, Solar Energy 48, 53-58, 1992.

[26] M.A. Khan, P.K. Rohatgi, Numerical solution to a moving boundary problem in a composite medium. Numerical Heat Transfer 25, 209221, 1994.

[27]J. Xie and C.Yuan, Numerical study of ice formation in ice thermal storage system using thin layer ring, Proceedings of 2013 International Symposium on Green Manufacturing and Applications, Honolulu, Hawaii, U.S.A., 2013.

[28]B. Halasz, M. Grozdek and V. Soldo, Development of computer program for simulation of an ice bank system operation, part I: mathematical modelling, international Journal of Refrigeration, 13231335, 2009.

[29] J. Xie and C. Yuan, Numerical study of thin layer ring on improving the ice formation of building thermal storage system, Applied Thermal Engineering , 69, 46-54, 2014.

[30]G. Taguchi, Taguchi on robust technology development, Bring Quality Engineering (QE) Upstream ASME, 1991.

[31]T. Mori, The New Experimental Design: Taguchi's Approach to Quality Engineering, ASI Press, 1990.

[32] G. Taguchi, A.E. Elsayed, C.H. Thomas, Quality Engineering in Production Systems, McGraw-Hill, New York, 1989.

[33]Egolf, P.W. and M. Kauffeld, From physical properties of ice slurries to industrial ice slurry applications. International Journal of Refrigeration, 28(1): p. 4-12, 2005.

[34]L., Wang, Z., Wang, R., Yang, Intelligent multiagent control system for energy and comfort management in smart and sustainable buildings, IEEE Transactions on Samrt Grid,3, 605$617,2012$.

[35]G. Taguchi, Introduction to quality engineering, Asian Productivity Organization, Tokyo, 1990.

[36] P.J. Ross, Taguchi techniques for quality engineering, McGraw-Hill, New York, 1988.

[37] K.-H. Hwang, K.-W. Lee, G.-J. Park, Robust optimization of an automobile rearview mirror for vibration reduction Struct. Multidisc. Optim., 21, pp. 300-308, 2001.

[38]H-G, Beyer and B. Sendhoff, Robust optimization - A comprehensive survey, Computer Methods in Applied Mechanics and Engineering, 196, 34-44, 2007.

[39]R.A. Fisher, Statistical methods for research worker, Oliver \& Boyd, London, 1925

[40]C.Y. Nian, W.H. Yang and Y.S. Tarng, Optimization of turning operations with multiple performance characteristics, J Mater Process Technology, 95, pp. 90-96, 1999. $c$

$\mathrm{C}_{\mathrm{s}}$

$\mathrm{C}_{\mathrm{l}}$

d

g

$h$

$h_{\text {reference }}$

$\rho$

$k$

K

$K_{0}$

L

P

$T_{\mathrm{f}}$

$u, v$

$U, V$

$x, y$

\section{Greek symbols \\ $\beta$ \\ $\mu$ \\ $\rho_{\mathrm{m}}$}

Subscripts
i
L
s
ref
W

specific heat, $\mathrm{J} / \mathrm{kg} \mathrm{K}$ specific heats of solid phase specific heats of liquid phase diameter of the cylinder acceleration of gravity, $\mathrm{m} / \mathrm{s}^{2}$ sensible enthalpy, $\mathrm{J} / \mathrm{kg}$ reference enthalpy density thermal conductivity, $\mathrm{W} / \mathrm{mK}$ Permeability, $\mathrm{m}^{2}$ empirical constant in KozenyCarman equation latent heat, $\mathrm{J} / \mathrm{kg}$ pressure, $\mathrm{Pa}$ time fusion temperature, $273.15 \mathrm{~K}$ $\mathrm{x}, \mathrm{y}$ direction velocity vector components $\mathrm{x}, \mathrm{y}$ direction dimensionless velocity-vector component Coordinate axes

liquid volume fraction dynamic viscosity, $\mathrm{N} \mathrm{s} / \mathrm{m}^{2}$ max density of water, 999.972 $\mathrm{kg} / \mathrm{m}^{3}$

initial condition

liquid phase solid phase reference value cylinder surface

\section{Nomenclature}

$\begin{array}{ll}\mathrm{A}_{\mathrm{i}} & \text { ice area } \\ \mathrm{A}_{\mathrm{c}} & \text { cylinder area }\end{array}$

